\title{
OPTIMALISASI DATA SURVEI SOSIAL EKONOMI NASIONAL (SUSENAS) DENGAN SMALL AREA ESTIMATION (SAE)
}

\author{
Studi Kasus: Estimasi Kemiskinan Level Desa di Kabupaten Belitung Timur \\ Tahun 2017 \\ (Survei Sosial Ekonomi Nasional (Susenas) Data Optimization With Small Area Estimation \\ $(S A E)$ \\ Case Study: Village Level Proverty Estimation in Belitung Timur Regency) \\ Uswatun Nurul Afifah', Royhan Faradis ${ }^{2}$ \\ 1,2 Badan Pusat Statistik Kabupaten Belitung Timur \\ Jl Raya Manggarawan Komplek Perkantoran Pemda Kecamatan Manggar Kabupaten Belitung Timur Provinsi \\ Kep Bangka Belitung \\ Email:uswatunnurula@bps.go.id
}

\begin{abstract}
ABSTRAK
Survei Sosial Ekonomi Nasional (Susenas) merupakan kegiatan survei yang diselenggarakan oleh Badan Pusat Statsistik (BPS). Data hasil Susenas menjadi produk yang strategis dan ditunggu karena memuat informasi terkait kondisi sosial, ekonomi, dan kependudukan suatu wilayah. Pemerintah Daerah (Pemda) adalah salah satu pihak yang menunggu hasil Susenas guna mengambil berbagai kebijakan tepat sasaran. Salah satu yang menjadi fokus Pemda adalah fenomena kemiskinan. Keadaan ini diperkuat dengan kebijakan Satu Data Indonesia oleh presiden Republik Indonesia yang memposisikan BPS sebagai sumber data kredibel. Akan tetapi, kebutuhan mendesak Pemda untuk mendapatkan informasi terutama kemiskinan di wilayahnya belum terpenuhi secara optimal karena keterbatasan cakupan data Susenas. BPS hanya dapat menyajikan data kemiskinan paling rendah di level Kabupaten sementara Pemda membutuhkan informasi lebih untuk kebijakan otonomi daerahnya sampe dengan level kecamatan bahkan desa. Penelitian ini bertujuan untuk menduga indikator kemiskinan yaitu pengeluaran perkapita di Kabupaten Belitung Timur di tingkat desa dengan model terbaik dan memetakan kemiskinan Belitung Timur di level kecamatan. Metode Small Area Estimation (SAE) pendekatan Empirical Best Linier Unbiased Predictors (EBLUP) tipe Fay-Harriot Model digunakan untuk mendapatkan pendugaan variabel kemiskinan di level desa dan kecamatan. Hasil penelitian menunjukkan bahwa jenis saluran pembuangan limbah cair keluarga dan keberadaan pasar desa mempengaruhi nilai pengeluaran perkapita. Selain itu, Kecamatan Dendang dan Simpang Pesak memiliki persentase penduduk miskin tertinggi berdasarkan pemetaan kemiskinan (proverty map).
\end{abstract}

Kata kunci: susenas, kemiskinan, Small Area Estimation (SAE), EBLUP

\section{ABSTRACT}

Survei Sosial Ekonomi Nasional (Susenas) is a survey activity carried out by the BPS-Statistics. Data from Susenas is a strategic product because it contains information related to social, economic and population conditions of an area. The Regional Government is one of the parties waiting for the results of the Susenas to take policy on target. This situation was strengthened by Indonesia's One Data policy by the president of the Republic of Indonesia which positioned BPS-Statistics as a credible data source. However, the urgent need for local governments to obtain information, especially poverty in their areas has not been optimally fulfilled because of the limited scope of Susenas data. BPS-Statistics can only present the lowest poverty data at the district level while the local government needs more information for its regional autonomy policy up to the sub-district or even village level. This study aims to predict poverty indicators, namely per capita expenditure in East Belitung Regency at the village level with the best model and to map East Belitung poverty at the district level. The Small Area Estimation (SAE) Empirical Best Linear Unlock Predictors (EBLUP) approach of the Fay-Hariot Model type is used to estimate poverty variables at the village and subdistrict levels. The results showed that the type of family wastewater disposal channel and the existence of village markets influence the value of per capita expenditure. In addition, Dendang and Simpang Pesak Districts have the highest percentage of poor people based on poverty mapping (proverty map).

Keywords: susenas, proverty, Small Area Estimation (SAE), EBLUP 


\section{PENDAHULUAN}

Survei Sosial Ekonomi Nasional (Susenas) merupakan kegiatan survei yang diselenggarakan oleh Badan Pusat Statistik (BPS) untuk mengumpulkan informasi terkait kondisi sosial, ekonomi dan kependudukan di suatu wilayah. Hasil data Susenas menjadi primadona bagi berbagai kalangan karena memuat informasi penting dari capaian target pembangunan seperti kemiskinan, gini ratio, dan indeks pembangunan manusia. Salah satu pengguna data yang bergantung pada data Susenas adalah Pemerintah Daerah (Pemda). Di era sekarang, Pemda sangat mengandalkan BPS dalam hal ketersediaan data guna mengambil kebijakan yang tepat sasaran. Hal ini diperkuat dengan Peraturan Presiden (Perpres) No 39 Tahun 2019 tentang Satu Data Indonesia (SDI) yang memposisikan BPS menjadi sumber data terpercaya untuk digunakan Pemda sebagai dasar kebijakan otonomi daerahnya. Akan tetapi, selama ini Susenas hanya mampu menyajikan informasi paling rendah sampai dengan tingkat kabupaten/kota. Kondisi ini tidak dapat mengakomodir permintaan Pemda yang membutuhkan informasi kemiskinan di tingkat kecamatan atau desa untuk kebijakan yang lebih tepat sasaran.

Angka kemiskinan di Kabupaten Belitung Timur pada tahun 2017 secara umum dapat dikategorikan rendah. Menurut BPS, persentase penduduk miskin di kabupaten yang terkenal dengan negeri laskar pelangi ini hanya sebesar 6,81 persen atau sekitar 8,44 ribu jiwa. Namun, kemiskinan di Kabupaten Belitung Timur menempati urutan ke-2 dengan persentase penduduk miskin tertinggi di Provinsi Kepulauan Bangka Belitung. Hal ini yang menjadi faktor penyebab Pemda Kabupaten Belitung Timur ingin mengetahui karakteristik kemiskinan secara lebih rinci. Oleh karena itu, informasi mengenai indikator kemiskinan yang bisa sampai dengan level desa dan kecamatan akan berguna untuk pembangunan daerah.

Estimasi indikator kemiskinan menggunakan data Susenas sampai dengan level desa dan kecamatan dibutuhkan dalam rangka menyajikan ketersediaan data secara optimal. Small Area Estimation (SAE) adalah metode yang tepat digunakan untuk memaksimalkan data Susenas guna mendapatkan estimasi hingga level desa atau kecamatan. Ningtyas, Rahayu (2015) dalam tesisnya menjelaskan bahwa metode EBLUP dapat estimasi parameter yang diamati lebih baik daripada estimator tidak langsung. Kriteria yang digunakan ialah dengan membandingkan Relative Root Mean Square (RRMSE) estimator langsung dengan estimator tidak langsung dengan metode EBLUP.

Hasil penelitian akan menjawab permasalahan yang dialami BPS Kabupaten Belitung Timur selama ini yaitu tidak mampu memenuhi permintaan data Pemda Belitung Timur di level kecamatan atau desa. Oleh karena itu, penilitian ini bertujuan untuk:

1. Menduga indikator kemiskinan Kabupaten Belitung Timur di tingkat desa dengan model terbaik2.

2. Memetakan kemiskinan Belitung Timur di level kecamatan.

\section{METODE}

Penelitian ini menggunakan data sekunder yaitu Susenas Maret 2017 Kabupaten Belitung Timur yang diperoleh dari BPS. Terdapat 23 desa dari 37 desa yang akan diteliti sesuai dengan sampel desa Susenas Maret 2017 dengan tujuh kecamatan yang semuanya terpilih menjadi smapek. Variabel yang digunakan yaitu pengeluaran perkapita penduduk per bulan dan keterangan status kemiskinan penduduk. Sementara itu, variabel penyerta yang digunakan berasal dari data PODE 2018.

Analisis yang digunakan untuk menduga indikator kemiskinan yaitu Small Area Estimation (SAE) dengan pendekatan EBLUP-Fay Hariot Model. Parameter yang akan diestimasi adalah pengeluaran perkapita dan jumlah penduduk miskin. Estimasi jumlah penduduk miskin digunakan untuk menghitung persentase penduduk miskin agar bisa memperlihatkan keterbandingan antar wilayah kecamatan. Variabel penyerta yang digunakan dalam penduga area kecil yaitu persentase pengguna listrik sebagai penerangan keluarga, jenis pembuangan limbah cair keluarga, dan keberadaan pasar desa.

Tahapan analisis yang digunakan dalam penelitian ini adalah sebagai berikut: 
1. Melakukan estimasi langsung terhadap variabel y yaitu pengeluaran perkapita dan jumlah penduduk miskin dari data Susenas dengan direct estimation yang telah diberi penimbang (weight) Susenas. Estimasi langsung dihitung dari software $R$.

2. Memilih variabel penyerta (Xi) yang berkorelasi secara signifikan terhadap variabel y melalui uji Korelasi Pearson:

$r=\frac{\left(n \sum X Y\right)-\left(\sum X \sum Y\right)}{\sqrt{\left[\left(n \sum X^{2}\right)-\left(\sum X\right)^{2}\right]\left[\left(n \sum Y^{2}\right)-\left(\sum Y\right)^{2}\right]}}$

dimana:

$r=$ korelasi pearson

$\mathrm{X}=$ variabel dependen

$Y=$ variabel independen

3. Melakukan pendugaan langsung dengan SAE-EBLUP menggunakan data variabel penyerta untuk membangun model. EBLUP adalah suatu model pendugaan parameter menggunakan General Linear Mixed (GLM) yang dirancang untuk peubah kontinu serta kurang cocok untuk data biner. Bentuk umum model GLM adalah:

$\hat{\theta}=X \beta+Z v+e$

Dimana:

$\hat{\theta}=$ vektor acak dari variabel respon yang terobservasi berukuran $\mathrm{n} \times 1$

$X=$ maktriks $(\mathrm{n} \times \mathrm{p}$ ) dari variabel prediktor yang elemen-elemennya diketahui

$\beta=$ vektor parameter bersifat tetap berukuran $\mathrm{p} \times 1$ yang tidak diketahui dan tidak terobservasi

$Z=$ matriks $(\mathrm{n} \times \mathrm{q})$ dari variabel prediktor yang elemen-elemennya diketahui

$v=$ vektor acak parameter yang tidak diketahui dan tidak terobservasi berukuran $\mathrm{q} \times 1$

$e=$ vektor random error yang tidak terobservasi berukuran $\mathrm{n} \times 1$

Model Fay-Herriot untuk model basic area level (Rao, 2003) adalah sebagai berikut:

$\hat{\theta}_{i}=x_{i}^{T} \beta+v_{i}+e_{i}, \mathrm{i}=1,2, \ldots, \mathrm{m}$

$=\theta_{i}+e_{i}$

dimana:

$x_{i}=$ vektor $\mathrm{px} 1$ variabel penyerta tingkat area

$v_{i}=$ pengaruh acak area kecil

$e_{i}=$ adalah error sampling.

Model Fay-Harriot kemudian digunakan dalam penaksiran parameter dengan menggunakan pendekatan EBLUP. Ketika $\sigma_{v}^{2}$ diketahui, maka EBLUP menjadi estimator Best Linier Unbiased Predictor (BLUP) sebagai berikut:

$\tilde{\theta}_{i}^{B L U P}=\gamma_{i} \hat{\theta}_{i}+\left(1-\gamma_{i}\right) x_{i}^{T} \tilde{\beta}$

dimana:

$\hat{\theta}_{i}=$ estimasi langsung dari area ke-i $(i=1, \ldots, m)$

$\mathrm{m}=$ jumlah area

$\gamma_{i}=\left(\frac{\sigma_{v}^{2}}{\varphi_{i}+\sigma_{v}^{2}}\right)$

$\sigma_{v}^{2}=$ varians dari pengaruh acak area

$\varphi_{i}=\operatorname{MSE}\left(\hat{\theta}_{i}\right)=\frac{s i^{2}}{n i}$

$s_{i}=$ standar deviasi dari area ke-i

$n_{i}=$ jumlah sampel area ke-i

$x_{i}=$ variabel penyerta area ke-i

$\hat{\beta}$ adalah koefisien regresi yang diduga dengan Generalized Least Square (GLS), yaitu 


$$
\hat{\beta}=\hat{\beta}\left(\sigma_{v}^{2}\right)=\left[\sum_{i=1}^{m} \frac{x_{i} x_{i}^{T}}{\varphi_{i}+\sigma_{v}^{2}}\right]^{-1}\left[\sum_{i=1}^{m} \frac{x_{i} \widehat{\theta}_{i}}{\varphi_{i}+\sigma_{v}^{2}}\right]
$$

4. Membandingkan hasil estimasi langsung dan SAE-EBLUP dari masing-masing variabel respon untuk dilihat besarnya RMSE

Setelah dicari nilai estimator BLUP, untuk mengukur seberapa baik estimator BLUP maka akan dicari nilai Mean Square Error (MSE) dengan rumus:

$\operatorname{MSE}\left(\tilde{\theta}_{I}^{B L U P}\right)=g_{1 i}\left(\sigma_{v}^{2}\right)+g_{2 i}\left(\sigma_{v}^{2}\right)$

Dimana:

$$
\begin{aligned}
& g_{1 i}\left(\sigma_{v}^{2}\right)=\frac{\sigma_{v}^{2} \varphi_{i}}{\varphi_{i}+\sigma_{v}^{2}}=\gamma_{i} \varphi_{i} \\
& g_{1 i}\left(\sigma_{v}^{2}\right)=\left(1-\varphi_{i}\right)^{2} x_{i}^{T}\left[\sum_{m}^{i} \frac{x_{i} x_{i}^{T}}{\varphi_{i}+\sigma_{v}^{2}}\right]^{-1} x_{i}
\end{aligned}
$$

Dalam praktiknya, varian pengaruh acak $\left(\sigma_{v}^{2}\right)$ tidak diketahui sehingga harus diduga terlebih dahulu. Salah satu metode yang dapat digunakan untuk estimasi varians pengaruh acak $\left(\sigma_{v}^{2}\right)$ adalah metode Maximum Likelihood $(\mathrm{ML})$ atau bisa juga dengan Residual Maximum Likelihood (REML). Sehingga diperoleh estimator baru yaitu: $\hat{\theta}_{i}^{B L U P}=\gamma_{i} \hat{\theta}_{i}+\left(1-\gamma_{i}\right) x_{i}^{T} \hat{\beta}$

Nilai Mean Square Error(MSE) digunakan untuk mengukur seberapa baik estimator EBLUP yaitu dengan rumus:

$\operatorname{MSE}\left(\hat{\theta}_{i}^{B L U P}\right)=g_{1 i}\left(\hat{\sigma}_{v}^{2}\right)+g_{2 i}\left(\hat{\sigma}_{v}^{2}\right)+2 g_{31}\left(\hat{\sigma}_{v}^{2}\right)$

Dimana:

$g_{1 i}\left(\hat{\sigma}_{v}^{2}\right)=\frac{\widehat{\sigma}_{v}^{2} \psi_{i}}{\widehat{\sigma}_{v}^{2}+}=\hat{\gamma}_{i} \psi_{i}$

$g_{2 i}\left(\hat{\sigma}_{v}^{2}\right)=\left(1-\hat{\gamma}_{i}\right)^{2} x_{i}^{T}\left[\sum_{i=1}^{m} x_{i} x_{i}^{T} /\left(\hat{\sigma}_{v}^{2}+\psi_{i}\right)\right]^{-1} x_{i}$

$g_{31}\left(\hat{\sigma}_{v}^{2}\right)=\psi_{i}^{2}\left(\psi_{i}+\hat{\sigma}_{v}^{2}\right)^{-3} \bar{V}\left(\hat{\sigma}_{v}^{2}\right)$

$\bar{V}\left(\hat{\sigma}_{v}^{2}\right)=2 m^{-2} \sum_{i=1}^{m}\left(\left(\psi_{i}+\hat{\sigma}_{v}^{2}\right)^{2}\right.$

Menurut Kurnia (2009), evaluasi hasil kajian menggunakan Relative Root Mean

Square Error (RRMSE) diperoleh dengan perhitungan sebagai berikut:

$\operatorname{RRMSE}\left(\hat{\theta}_{i}^{B L U P}\right)=\frac{\sqrt{M S E\left(\widehat{\theta}_{i}^{B L U P}\right)}}{\widehat{\theta}_{i}^{B L U P}} \times 100 \%$

5. Menghitung estimasi SAE-EBLUP jumlah penduduk miskin dengan tahapan analisis seperti tahap 1 sampai dengan tahap 4. Hasil data Susenas telah menentukan penduduk miskin dan tidak miskin berdasarkan rata-rata pengeluaran perkapita. Kemudian menghitung persentase penduduk miskin dengan jumlah penduduk kondisi 2017 yang diperoleh dari BPS (2018). Persentase penduduk miskin digunakan agar memberikan gambaran perbandingan antar wilayah yaitu antar kecamatan. Berdasarkan hasil tersebut, kecamatan diklasifikasikan ke dalam tiga kategori kemiskinan. Pengklasifikasian ini dibagi ke dalam tiga kategori yaitu kategori rendah, sedang, dan tinggi. Klasifikasi didasarkan pada sebaran data persentase penduduk miskin masing-masing kecamatan.

6. Memetakan Kabupaten Belitung Timur berdasarkan kecamatan yang diklasifikasikan berdasarkan kategori tingkat kemiskinan hasil pendugaan dari SAE-EBLUP menggunakan software Geographic Information Systems (GIS). Rao,J.N.K.,dkk. (2014) dalam papernya yang berjudul "A Comparison of Small Area Estimation 
Methods for Poverty Mapping", memetakan kemiskinan populer berfokus pada aspek praktis dengan mensimulasikan perbandingan metode-metode yang digunakan dengan mendeskripsikan estimator langsung. Haining (2000) mengungkapkan bahwa SIG dalam pemetaan kemiskinan dapat digunakan tidak hanya untuk memvisualkan data spasial dalam bentuk peta, tetapi juga sebagai alat untuk mengekstrak informasi dari dataset. SIG lebih mudah dipahami secara visualisasi daripada numerik atau statistik.

\section{HASIL DAN PEMBAHASAN}

\section{Pendugaan Pengeluaran Perkapita}

Desa yang diteliti berjumlah 23 desa sesuai dengan desa yang terpilih sebagai sampel pada Susenas 2017. Oleh karena itu, bahasan penelitian ini dibatasi sampai dengan 23 desa. Berdasarkan hasil penghitungan dengan penduga langsung didapatkan data sebaran pengeluaran perkapita level desa berdistribusi normal ditunjukkan dalam gambar boxplot berikut:

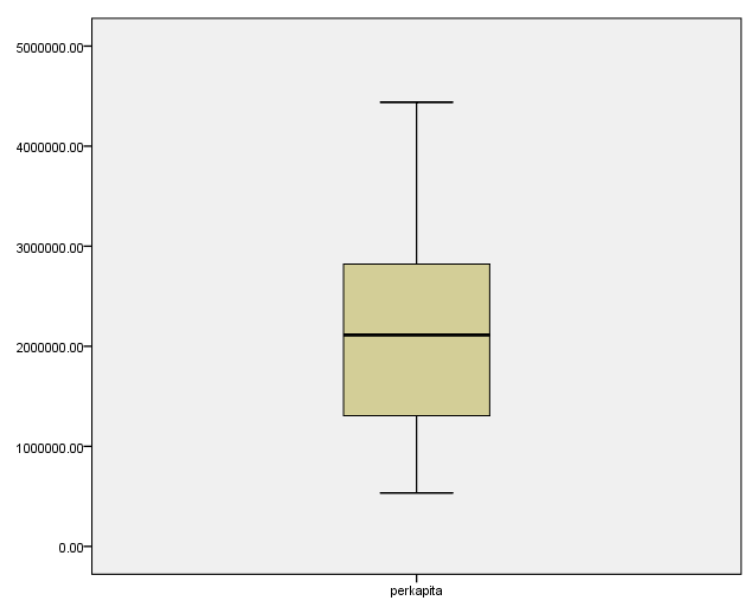

Gambar 1. Boxplot pengeluaran perkapita perbulan level desa, Tahun 2017.

Data pengeluaran perkapita desa dinyatakan normal secara signifikan dengan uji KolmogorovSmirnov (D) 0,085 lebih kecil dibandingkan dengan nilai kritis Kolmogorov-Smirnov 0,327 dengan pvalue sebesar 0,9367 pada tingkat signifikasi $5 \%$. Berdasarkan perhitungan pendugaan langsung, rata-rata pengeluaran perkapita per bulan di Kabupaten Belitung Timur pada tahun 2017 sebesar Rp2.199.043.

Setelah dilakukan training dan testing didapatkan variabel penyerta $(X)$ yang secara signifikan berpengaruh terhadap pengeluaran perkapita. Variabel hasil Pendataan Potensi Desa (PODES) yaitu jenis jenis saluran pembuangan limbah cair dari air mandi/cuci sebagian keluarga $\left(\mathrm{X}_{1}\right)$ dan keberadaan serta fungsi pasar desa $\left(\mathrm{X}_{2}\right)$. Seperti halnya yang telah disampaikan BPS (2002) bahwa beberapa faktor yang diduga menjadi penyebab kemiskinan suatu desa yaitu faktor alam/lingkungan, faktor kelembagaan, faktor sarana dan prasarana dan akses, serta faktor sosial ekonomi penduduk. Statistik dari hubungan pengeluaran kapita (y) dengan variabel penyerta (xi) yang diambil dari pendataan PODES disajikan dalam Tabel 1 berikut ini: 
Tabel 1. korelasi penyerta dengan pengeluaran perkapita desa.

\begin{tabular}{ccc}
\hline Variabel Penyerta $(X)$ & Korelasi & p-value \\
\hline $\begin{array}{c}\text { Jenis Pembuangan } \\
\text { limbah cair }\left(X_{1}\right)\end{array}$ & 0,766 & 0,035 \\
$\begin{array}{c}\text { Keberadaan dan Fungsi } \\
\text { Pasar Desa }\left(X_{2}\right)\end{array}$ & 0,862 & 0,026 \\
\hline
\end{tabular}

Variabel penyerta $\left(X_{i}\right)$ kemudian digunakan untuk menduga pengeluaran perkapita desa mengggunakan metode SAE pendekatan EBLUP Fay-Harriot. EBLUP FH dipilih dibandingkan EBLUP REML karena memiliki kesesuasian model yang lebih baik dilihat dari nilai AIC, BIC, dan KIC keduanya. Model terbaik yang diperoleh untuk menduga pengeluaran perkapita desa adalah sebagai berikut:

$$
\hat{y}=31826-548890 X_{1}-1164727 X_{2}
$$

Berdasarkan model tersebut, jenis pembuangan limbah cair kebanyakan keluarga $\left(X_{1}\right)$ di lubang atau tanah terbuka akan menurunkan pengeluaran perkapita atau jenis pendapatan penduduk. Pengeluaran perkapita yang semakin mengecil menandakan bahwa pendapatan penduduk tersebut juga kecil sehingga lebih berpotensi untuk miskin. Sementara itu, tidak adanya pasar desa yang berfungsi $\left(\mathrm{X}_{2}\right)$ juga menyebabkan pengeluaran perkapita per bulan berkurang di desa tersebut. Hal ini dikarenakan pasar desa merupakan pusat perekonomian yang menciptakan kegiatan ekonomi. Tidak adanya pasar desa membuat suatu desa lesu perekonomian yang berdampak pada rendahnya pendapatan (pengeluaran perkapita) sehingga berpotensi juga untuk miskin.

Nilai rata-rata pengeluaran perkapita per bulan berdasarkan estimasi langsung sebesar Rp2.199.043 per bulan. Sedangkan untuk pendugaan mengggunakan SAE EBLUP diperoleh nilai rata-rata sebesar Rp2.008.690 perkapita per bulan. Berikut ini adalah perbandingan nilai estimasi langsung dengan estimasi EBLUP:

Tabel 2. perbandingan nilai pengeluaran perkapita masing-masing desa antara estimasi langsung dengan EBLUP (rupiah).

\begin{tabular}{cccc}
\hline No & Nama Desa & Estimasi Langsung & Estimasi EBLUP \\
\hline 1 & JANGKANG & 3.717 .172 & 3.717 .171 \\
2 & NYURUK & 2.096 .174 & 1.924 .712 \\
3 & BALOK & 1.171 .805 & 1.229 .529 \\
4 & TANJUNG BATU ITAM & 1.570 .066 & 1.688 .867 \\
5 & DUKONG & 3.122 .395 & 2.836 .669 \\
6 & LILANGAN & 1.440 .923 & 1.560 .941 \\
7 & JANGKAR ASAM & 2.638 .389 & 1.946 .967 \\
8 & SELINGSING & 4.438 .835 & 3.455 .930 \\
9 & LIMBONGAN & 2.111 .941 & 1.863 .971 \\
10 & LINTANG & 890.168 & 1.070 .720 \\
11 & SIMPANG TIGA & 2.391 .820 & 1.962 .570 \\
12 & KELUBI & 1.010 .418 & 1.067 .231 \\
13 & PADANG & 2.050 .635 & 2.046 .307 \\
14 & LALANG & 533.430 & 573.045 \\
15 & LALANG JAYA & 3.660 .250 & 2.951 .977 \\
16 & KURNIA JAYA & 2.810 .237 & 2.296 .742 \\
17 & BARU & 2.141 .601 & 2.111 .112 \\
18 & SUKAMANDI & 4.343 .720 & 3.710 .743 \\
19 & BUDING & 2.642 .738 & 2.641 .857 \\
20 & MENTAWAK & 628.919 & 722.300 \\
21 & SENYUBUK & 2.831 .158 & 2.547 .057 \\
22 & MAYANG & 1.787 .982 & 1.679 .972 \\
23 & PEMBAHARUAN & 547.224 & 593.482 \\
\hline
\end{tabular}

Metode pendugaan dengan SAE-EBLUP lebih baik dibandingkan dengan pendugaan langsung karena memiliki RRMSE yang lebih kecil. Berdasarkan perhitungan, RMSE SAE-EBLUP sebesar 0,2718 
sedangkan RMSE Pendugaan langsung sebesar 0,3162. Oleh karena itu, dapat dikatakan bahwa pendugaan pengeluaran perkapita dengan menggunakan data susenas untuk level desa metode SAE-EBLUP lebih baik dibandingkan dengan pendugaan langsung.

\section{Pemetaan Kemiskinan}

Pemetaan kemiskinan (proverty map) merupakan solusi bagi Pemda Kabupaten Belitung Timur untuk mengambil kebijakan yang tepat sasaran. Dalam memetakan kemiskinan, penelitian ini akan fokus pada kemiskinan di tingkat kecamatan dikarenakan keterbatasan sampel Susenas yang tidak mencakup semua desa. Selain itu, semua kecamatan yang ada di Kabupaten Belitung Timur terpilih menjadi sampel Susenas Maret 2017. Tujuh kecamatan yang ada di Kabupaten Belitung Timur diklasifikasikan ke dalam tiga kategegori berdasarkan persentase kemiskinan yang dihitung berdasarkan estimasi jumlah penduduk miskin. Kategori 1 adalah kecamatan dengan jumlah penduduk miskin terkecil; Kategori 2 adalah kecamatan dengan persentase rumah tangga miskin sedang; dan kategori 3 adalah kecamatan dengan persentase rumah tangga miskin terbesar.

Tabel 3. Kategori kemiskinan kecamatan berdasarkan persentase penduduk miskin

\begin{tabular}{cccc}
\hline Kategori & Tipe Kemiskinan & Kecamatan & $\begin{array}{c}\text { Persentase Kemiskinan } \\
(\%)\end{array}$ \\
\hline 1 & Rendah & Simpang Renggiang, Damar, Manggar, & $<10$ \\
2 & Kelapa Kampit & $10-20$ \\
3 & Tinggi & Gantung & $>20$ \\
\hline
\end{tabular}

Klasifikasi kemiskinan berdasarkan Tabel 3 kemudian disajikan dalam peta kemiskinan (proverty map) menggunakan GIS.

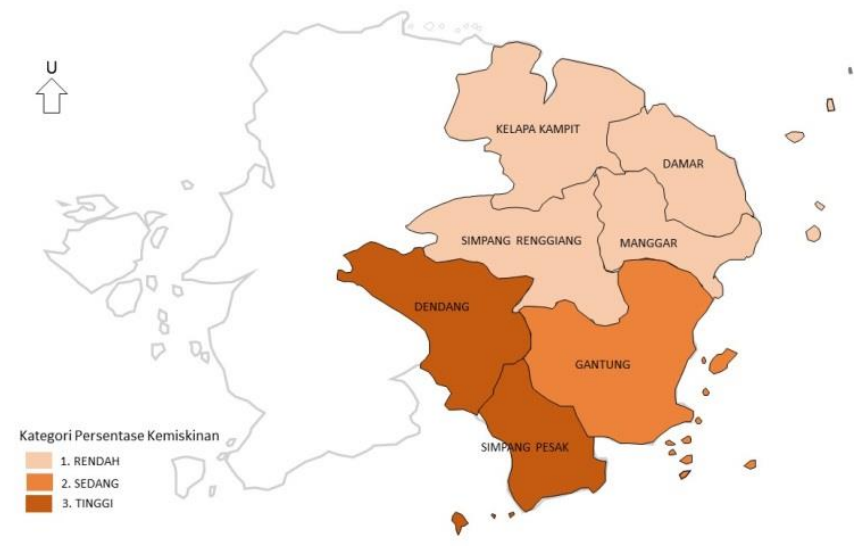

Gambar 2. Peta kemiskinan kecamatan di Kabupaten Belitung Timur, Tahun 2017.

Berdasarkan Gambar 2, kecamatan dengan persentase ruta miskin terbesar yaitu Dendang dan Simpang Pesak. Lebih rinci, Kecamatan Dendang memiliki 34,45 persen penduduk miskin sementara Kecamatan Simpang Pesak memiliki 54,25 persen penduduk miskin. Hal ini menunjukkan bahwa rendahnya persentase kemiskinan di Kabupaten Belitung Timur tidak merata untuk semua wilayah. Kesejahteraan penduduk mengelompok pada kecamatan tertentu. Selain itu, besarnya persentase penduduk miskin di dua kecamatan tersebut disebabkan oleh beberapa faktor. Faktor pertama yaitu letak geografis, kedua kecamatan tersebut memiliki jarak yang paling jauh dari pusat pemerintahan di Kabupaten Belitung Timur yang terletak di Kecamatan Manggar. Kecamatan Dendang memiliki jarak km dan kecamatan Simpang Pesak berjarak..... dari Kecamatan Manggar. Selain itu, di Kecamatan Dendang masih terdapat 1,3 persen keluarga yang belum menggunakan listrik sebagai sumber penerangan utama. Ketidakadaan listrik merupakan salah satu faktor penyebab kemiskinan. 


\section{KESIMPULAN}

Berdasarkan estimasi langsung, rata-rata pengeluaran perkapita sebesar Rp2.199.043 per bulan. Pengeluaran perkapita tertinggi terletak di Desa Selinsing yaitu Rp4.438.835 per bulan. Sedangkan pada estimasi SAE-EBLUP diperoleh rata-rata pengeluaran perkapita sebesar Rp2.008.690 per bulan. Desa Jangkang memiliki rata-rata pengeluaran perkapita tertinggi yaitu Rp3.717.171 per bulan. Penduga area kecil EBLUP menghasilkan nilai RRMSE yang lebih kecil dibandingkan nilai RRMSE pendugaan langsung. Nilai RRMSE EBLUP sebesar 0,2718 dan nilai RRMSE pendugaan langsung sebesar 0,3162.

Berdasarkan peta kemiskinan (proverty map). Kecamatan Dendang dan Simpang Pesak merupakan kecamatan dengan persentase penduduk miskin tertinggi. Dua kecamatan tersebut memiliki persentase jumlah penduduk miskin di atas 20 persen. Tingginya selisih (gap) persentase jumlah penduduk miskin merupakan signal bahwa kesejahteraan belum merata.

\section{DAFTAR PUSTAKA}

Badan Pusat Statistik. (2018). Statistik Kesejahteraan Provinsi Kepulauan Bangka Belitung Tahun 2017. Pangkalpinang: BPS

Badan Pusat Statistik. (2018). Kepulauan Bangka Belitung Dalam Angka Tahun 2018. Pangkalpinang: BPS

Badan Pusat Statistik. (2018). Kabupaten Belitung Timur Dalam Angka.Tahun 2018. Manggar: BPS

Badan Pusat Statistik. (2018). Statistik Kesejahteraan Rakyat Kabupaten Belitung Timur Tahun 2017. Manggar: BPS

Haining, R. (2003). Spatial Data Analiysis: Theory and Practice. UK: The Cambride University Perss.

J.N.K. Rao, Guadarrama, M., Molina, I., Rao, J. N. K., \& Gauri Sankar Dtta. (2015). Small Area Estimation Under A Fay-herriot Model with Premilinary Testing for The Presence of Random Area Effects.

J. Supranto. (2008). Statistika Teori dan Aplikasi, edisi ketujuh. Jakarta: Penerbit: Erlangga.

Kurnia, A. (2009). Prediksi Terbaik Empirik Untuk Model Transformasi Logaritma di Dalam Pendugaan Area Kecil dengan Penerapan pada Data Susenas. Bogor: IPB

Ningtyas, R., Rahmawati., R., \& Wilandari, Y. (2015). Penerapan Metode Empirical Best Linier Unbiased pada Model Penduga Area Kecil dalam Pendugaan Pengeluaran Perkapita di Kabupaten Belitung Timur. Jurnal Gaussian Volume 4 Nomor 4, 977-986.

Rao, J. (2003). Small Area Estimation. United States of America: John Wiley \& Sons, Inc.

Prahasta, E. (2009). Sistem Informasi Geografis: Konsep-konsep dasar (Perspektif Geodesi \& Geomatika). Bandung: Penerbit Informatika. 